\title{
Arterial plasma norepinephrine correlates to blood pressure in middle-aged men with sustained essential hypertension
}

\begin{abstract}
Increased plasma catecholamine levels assessed from the venous blood have been found in a number of studies of younger patients with essential hypertension, but hypertensivenormotensive differences could not easily be demonstrated in subjects above $\mathbf{4 0}$ years of age. For several reasons, measurement of arterial plasma catecholamines may be a more sensitive tool for the detection of hypertensive-normotensive differences. The present study therefore aimed at examining both venous and arterial plasma catecholamines in a group of white men, all 50 years of age, with never-treated, established essential hypertension ( $n=61$, blood pressure $165 \pm 2 / 112 \pm 1 \mathrm{~mm} \mathrm{Hg}$, means $\pm S E$ ) and comparing them with a similar group of normotensive men $(n=51$, blood pressure $128 \pm 1 / 85 \pm 1 \mathrm{~mm} \mathrm{Hg}$ ). Arterial and venous plasma epinephrine, heart rate, and body weight were significantly elevated in the hypertensive group. Plasma norepinephrine was similar between the groups in the venous blood, whereas in the arterial blood the values in hypertensive subjects were moderately, but significantly increased $(p<0.03)$. However, stepwise multiple regression analysis suggested arterial plasma norepinephrine was the only significant independent explanatory variable of raised blood pressure in the hypertensive group $(r=0.51, t=4.05, p=0.0002)$. Such a relationship was not found in the normotensive group. Thus based on measurements in arterial blood, we conclude that plasma norepinephrine, representing sympathetic tone, may be an important pathogenetic factor for high blood pressure in middle-aged men with established hypertension. (AM HEART J 1989;118:775.)
\end{abstract}

Sverre E. Kjeldsen, MD, Nicholas J. Schork, BA, Paul Leren, MD, and Ivar K. Eide, MD. Oslo, Norway, and Ann Arbor, Mich.

Plasma norepinephrine has been taken as an index of sympathetic activity. Approximately $50 \%$ of plasma norepinephrine in forearm venous blood comes from local release, mainly from the vascular sympathetic nerve terminals in muscle tissue. ${ }^{1}$ In normotensive men, Wallin et al. ${ }^{2}$ found a positive correlation between norepinephrine in forearm venous blood and muscle sympathetic activity. In hypertensive individuals, forearm muscle sympathetic activity seems to be normal, ${ }^{3}$ and forearm venous plasma norepinephrine has been found to be unchanged in a number of studies on hypertensive subjects. ${ }^{4}$

However, 25 of the 64 studies reviewed by

From the Department of Internal Medicine, Ullevaal University Hospital, Oslo; and the Department of Internal Medicine, Division of Hypertension, the University of Michigan Medical Center, Ann Arbor.

This study was supported by the Norwegian Council on Cardiovascular Diseases.

Received for publication Dec. 20, 1988; accepted June 2, 1989.

Reprint requests: Sverre E. Kjeldsen, MD, Dept. of Internal Medicine, Ullevaal Hospital, N-0407 Oslo 4, Norway.

$\mathbf{4} / \mathbf{1} / \mathbf{1 4 5 4 5}$
Goldstein ${ }^{4}$ showed significantly increased forearm venous plasma norepinephrine in essential hypertension, and 52 studies reported higher levels in the hypertensive subjects. There is an increased spillover of norepinephrine to plasma from the heart and kidneys in essential hypertension. ${ }^{5}$ Venous effluents from all organs are completely mixed in arterial blood. Venous spillover of norepinephrine from the heart and kidneys in essential hypertension ${ }^{5}$ is more likely to be detected in arterial plasma than in peripheral venous blood in the forearm, since the large normal uptake and release of norepinephrine by the forearm, both approximately $50 \%$ of the arterial concentration, 1 may dampen an increased concentration from the arterial side. Increased arterial plasma norepinephrine may then raise forearm vascular resistance in hypertension by $\alpha$-adrenergic stimulation. ${ }^{6}$ In addition, measurements of peripheral venous plasma norepinephrine may sometimes conceal important hypertensive-normotensive differences. ${ }^{7}$ When the arterial concentrations are considerably increased, higher levels though reduced, may still be detectable 
Table I. Supine blood pressure (BP), heart rate (HR), and other characteristics of hypertensive and normotensive groups (means $\pm \mathrm{SE}$ )

\begin{tabular}{|c|c|c|}
\hline & $\begin{array}{c}\text { Ilypertensive } \\
\text { sroup } \\
(n=61)\end{array}$ & $\begin{array}{c}\text { Normolerisive } \\
\text { group } \\
(n=51)\end{array}$ \\
\hline Systolic BP (mm Hg) & $165 \pm 2$ & $128 \pm 1^{*}$ \\
\hline Diastolic BP (mm Hg) & $112 \pm 1$ & $85 \pm 1^{*}$ \\
\hline Mean BP $(\mathrm{mm} \mathrm{Hg})$ & $130 \pm 1$ & $100 \pm 1^{*}$ \\
\hline HR (heats/min) & $69 \pm 2$ & $62 \pm 1 \uparrow$ \\
\hline Height $(\mathrm{cm})$ & $180 \pm 1$ & $179 \pm 1(\mathrm{~ns})$ \\
\hline Body weight (kg) & $86 \pm 2$ & $78 \pm 1^{*}$ \\
\hline $\begin{array}{l}\text { Body mass index } \\
\left(\mathrm{kg} / \mathrm{m}^{2}\right)\end{array}$ & $26.6 \pm 0.4$ & $24.3 \pm 0.3^{*}$ \\
\hline $\begin{array}{l}\text { Sodium excretion } \\
(\mathrm{mmol} / 24 \mathrm{hr})\end{array}$ & $168 \perp 7$ & $173 \pm 9$ (ns) \\
\hline $\begin{array}{l}\text { Potassium excretion } \\
\text { (mmol/24 hr) }\end{array}$ & $84 \pm 3$ & $83 \pm 3(\mathrm{~ns})$ \\
\hline $\begin{array}{l}\text { Creatinine clearance } \\
\text { (ml/min per } 1.73 \mathrm{~m}^{2} \\
\text { body surface) }\end{array}$ & $118 \pm 3$ & $111 \pm 3(\mathrm{~ns})$ \\
\hline
\end{tabular}

All subjects were white men, 50 years of age.

${ }^{*} p<0.001:+p<0.01$ between groups; ns, not significant.

on the forearm venous side, which may explain many of the controversies in the literature. ${ }^{4}$ This also implies that a negative study based on measurements of norepinephrine in forearm venous plasma may be of less value in assessing hypertensive-normotensive differences in sympathetic tone.

The review by Goldstein ${ }^{4}$ claimed disappearance of or lower hypertensive-normotensive norepinephrine differences in persons aged above 40 years. However, the results were based on measurements of norepinephrine in peripheral venous blood. Therefore the present study aimed at testing our hypothesis ${ }^{7}$ that measurement of arterial plasma catecholamines may be a more sensitive tool for the detection of hypertensive-normotensive differences. We simultaneously measured plasma norepinephrine in arterial and forearm venous blood in a fairly large group of white men, all 50 years of age, with never-treated, established essential hypertension, and in age- and race-matched normotensive men. Arterial and venous plasma norepinephrine were compared between the two groups; within each group, the effects of plasma norepinephrine and other parameters such as plasma epinephrine, heart rate, body weight, and electrolyte excretions on blood pressure were measured by stepwise multiple regression analysis.

\section{METHODS}

Hypertensive patients. Sixty-one white men, all 50 years old with never-treated, established essential hypertension of WHO group I classification, were recruited from the Oslo Study of Cardiovascular Diseases, a large epidemiologic study in the county of Oslo, Norway. ${ }^{8}$ Six to 10 years prior to the present investigation, they had systolic blood pressure below $150 \mathrm{~mm} \mathrm{Hg}$ and diastolic blood pres sure above $90 \mathrm{~mm} \mathrm{Hg}(143+1 / 97 \pm 1 \mathrm{~mm} \mathrm{Hg})$. At the time of the present study, they had stable blood pressure above $150 / 100 \mathrm{~mm} \mathrm{Hg}$. Further characteristics including heart rate, body weight, electrolyte excretion, and creatinine clearance at the time of the present study are given in ' $\mathrm{Ta}$ ble I. They had normal ocular fundi, electrocardiograms (ECGs), chest x-ray films, and kidney function was normal as estimated by creatinine clearance and urinalysis.

Normotensive control subjects. The hypertensive men were compared with 51 healthy white men, all 50 years old, also recruited from the Oslo Study of Cardiovascular Diseases. ${ }^{8}$ Six to 10 years prior to the present investigation, their blood pressure averaged $124 \pm 2 / 78 \pm 1 \mathrm{~mm} \mathrm{Ho}$, and later their blood pressure remained below $140 / 90 \mathrm{~mm} \mathrm{Hg}$. Table I shows the characteristics of these men at the time of the present study. These men also had normal ocular fundi, ECGs, chest $x$-ray films, and kidney function was normal as estimated by creatinine clearance and urinalysis.

Protocol. The study was approved by the Ethics Committee of Ullevaal Hospital, University of Oslo. Informed consent was obtained from patients and control subjects. All subjects were outpatients and had regular daily employment. For 6 to 10 years they had been familiar with clinical examination, blood pressure recording, and blood sampling. None were addicted to alcohol or were taking any drugs, and they abstained from alcohol for at least 2 days before blood sampling. The examinations were carried out between 8 and $9 \mathrm{AM}$ following overnight fasting without intake of fluid, food, nicotine, or caffeine after $12 \mathrm{AM}$. They were permitted to drink one glass of water in the morning before examination. Only one subject was examined each day, and all by the same physician. Hypertensive and normotensive subjects were examined in a random order. Immediately preceding the examination, a 24-hour urine specimen was collected for urinalysis and determination of creatinine and electrolytes.

Patients and controls rested supine for 30 minutes in a quiet room in the presence of the examining physician only. The room temperature was $20^{\circ} \mathrm{C}$. After this supine resting period, systolic and fifth phase diastolic blood pressure were measured as the average of two readings with a mercury sphygmomanometer. The heart rate was counted for 1 minute. Immediately thereafter, $5 \mathrm{ml}$ of venous blood for catecholamines was drawn from the median cubital vein with a 21-gauge needle, and $5 \mathrm{ml}$ of arterial blood for catecholamines was obtained by puncture of the fernoral artery with a hypodermic 23 -gauge needle (this was barely felt by the subjects).

Blood was drawn into polypropylene syringes and was immediately transferred to ice-chilled tubes with glutathione and ethyleneglycol-bis-( $\beta$-aminoethylether). $\mathrm{N}, \mathrm{N}, \mathrm{N}^{\prime}, \mathrm{N}^{\prime}$-tetraacetic acid (EGTA) and kept on melting ice. Within 1 hour, the samples were centrifuged at $4^{\circ} \mathrm{C}$, and the plasmas were frozen at $-70^{\circ} \mathrm{C}$.

Analytical methods. Plasma norepinephrine and epinephrine were measured with a radioenzymatic technique according to that devised by Peuler and Johnson, ${ }^{9}$ as previously reported. ${ }^{1 "}$ For the two catecholamines, respec- 
tively, this assay showed coefficients of variation of $9 \%$ and $13 \%$ between single assays performed on different days in 25 plasma samples. An equal number of hypertensive and normotensive subject plasma samples were assayed within each daily set-up. Creatinine and electrolytes were determined on a Technicon sequential multiple analyzer (SMA) 12/60 AutoAnalyzer (Technicon Instruments Corp., 'Iarrytown, N.Y.). The technicians performing the assays were unaware of the patients' blood pressure status.

Statistical methods. The data were analyzed with the "MIDAS" statistical package on the University of Michigan's IBM 3090-600E computer (IBM Corp., Health Industry Marketing Division, Atlanta, Ga.). A two-tailed Student's $t$ test for unpaired samples and Pearson's correlation coefficients were used for univariate analyses. For multivariate analyses, stepwise multiple regression analysis was applied for determining independent factors related to blood pressure. The level of statistical significance was set at $p \leq 0.05$.

\section{RESULTS}

Blood pressure, heart rate, body weight, electrolyte excretion, and creatinine clearance. Mean blood pressure was $30 \%$ higher in the hypertensive group than in the normotensive group following 30 minutes of supine rest (Table I), while resting heart rate was $12 \%(p<0.01)$ higher in the hypertensive group. Body mass index was $9 \%(p<0.001)$ higher in the hypertensive group, while there was no statistical difference in the 24-hour urinary excretion of sodium and potassium or in creatinine clearance.

Plasma catecholamines. Plasma norepinephrine in forearm venous blood averaged $346 \pm 22 \mathrm{pg} / \mathrm{ml}$ in the hypertensive group versus $303 \pm 11 \mathrm{pg} / \mathrm{ml}$ in the normotensive group (Fig. 1). This difference did not reach statistical significance $(p>0.1)$, while the arterial plasma norepinephrine, $332 \pm 19 \mathrm{pg} / \mathrm{ml}$, was significantly increased compared with $278 \pm 12 \mathrm{pg} /$ $\mathrm{ml}$ in the normotensive group $(p<0.03)$. Both arterial $(116 \pm 10 \mathrm{pg} / \mathrm{ml})$ and venous $(52 \pm 4 \mathrm{pg} / \mathrm{ml})$ plasma epinephrine concentrations in the hypertensive group (Fig. 1) were highly significantly elevated over the corresponding concentrations (74 \pm 4 and $34 \pm 2 \mathrm{pg} / \mathrm{ml}$, respectively) in the normolensive group ( $p<0.001)$.

Correlations with blood pressure. Mean blood pressure correlated positively and significantly with arterial plasma norepinephrine $(r=0.50, p<0.001$, Fig. 2), venous plasma norepinephrine $(r=0.47$, $p<.001)$, and arterial plasma epinephrine $(r=0.32$, $p<0.02$ ) in the hypertensive study group. Essentially the same correlation coefficients appeared between systolic and diastolic blood pressure and these plasma catecholamines. No significant correlation was found between blood pressure and heart rate, body mass index, electrolyte excretion, creatinine clearance, or venous plasma epinephrine. Stepwise multiple re-

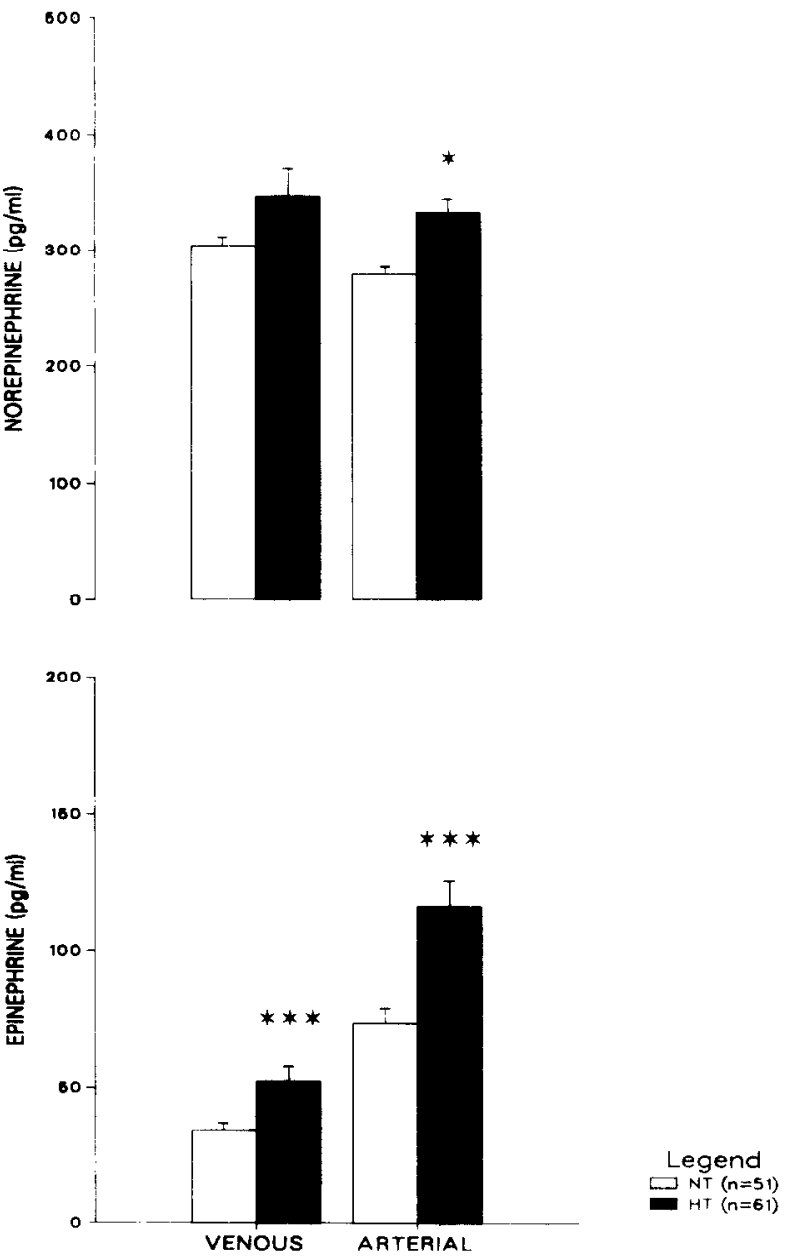

Fig. 1. Plasma catecholamines in antecubital venous blood (VENOUS) and in arterial blood (ARTERIAL) in normotensive $(N T)$ and hypertensive (HT) groups. ${ }^{*} p<0.03$ and ${ }^{* * *} p<0.001$ indicate significant differences between groups.

gression analysis suggested that arterial plasma norepinephrine was the only significant independent explanatory variable of blood pressure in the hypertensive group (mean blood pressure: $r=0.51$, $t=4.05, p=0.0002$; Table II). No variable correlated with blood pressure in the normotensive group.

Correlations between norepinephrine, epinephrine, heart rate and body mass index. In the hypertensive group, there were relatively strong positive correlations between norepinephrine, epinephrine, and heart rate; e.g., arterial norepinephrine correlated with arterial $(r=0.65, p<0.001$, Fig. 3$)$ and venous epinephrine $(r=0.55, p<0.001)$ and with heart rate $(r=0.58, p<0.001)$. Both arterial $(r=0.30, p<0.03)$ and venous $(r=0.39, p<0.003)$ epinephrine correlated with heart rate. In this group, arterial plasma epinephrine correlated negatively with body mass index $(r=-0.27, p<0.05)$. In addition, in the normotensive group, arterial norepinephrine correlated 


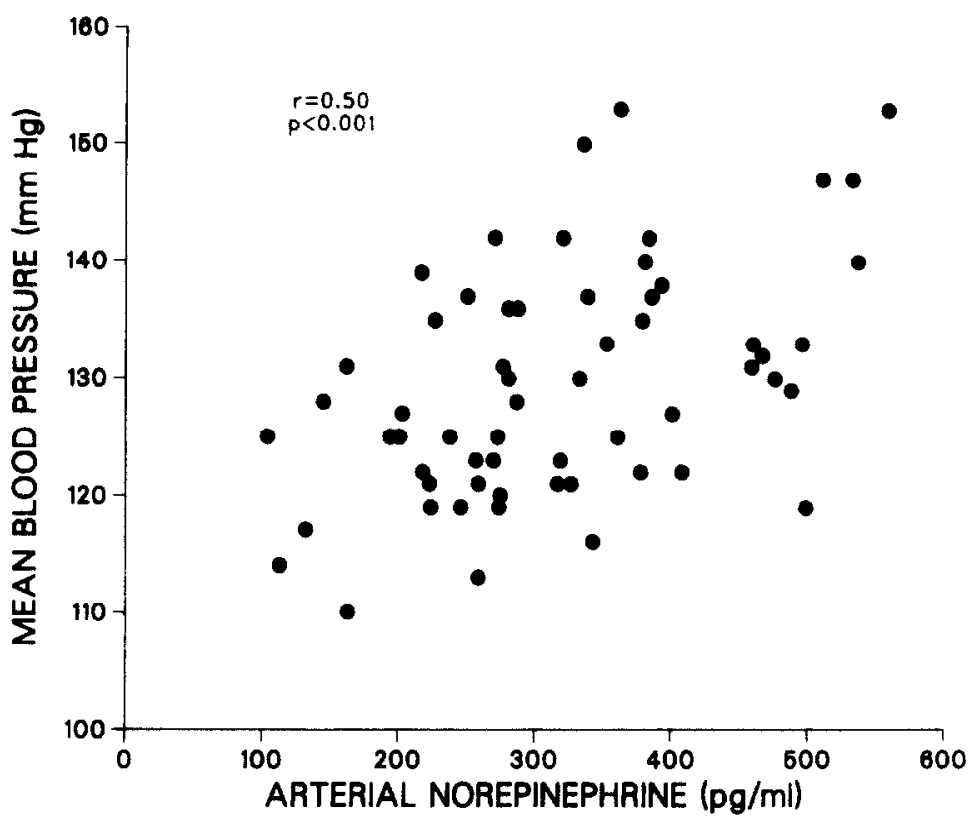

Fig. 2. Correlation between arterial plasma norepinephrine concentration and mean arterial blood pressure in the hypertensive group.

Table II. Cumulative multiple correlation and $r^{2}$ coefficients (amount of variability in mean blood pressure explained) when mean blood pressure is considered to be the independent variable in the hypertensive group

\begin{tabular}{lcc}
\hline & $\begin{array}{c}\text { Cumulative } \\
\text { multiple } \\
\text { correlation } \\
\text { coefficients }\end{array}$ & $\begin{array}{c}\text { Cumulative } \\
\text { multiple } \\
r^{2} \\
\text { coefficients }\end{array}$ \\
\hline Arterial norepinephrine & $0.5068^{*}$ & $0.2568^{*}$ \\
Urinary potassium excretion & 0.5270 & 0.2777 \\
Venous epinephrine & 0.5453 & 0.2974 \\
Body height & 0.5585 & 0.3120 \\
Urinary sodium excretion & 0.5633 & 0.3173 \\
Creatinine clearance & 0.5661 & 0.3205 \\
Venous norepinephrine & 0.5677 & 0.3222 \\
Arterial epinephrine & 0.5690 & 0.3237 \\
Heart rate & 0.5697 & 0.3245 \\
Body weight & 0.5697 & 0.3245 \\
\hline
\end{tabular}

${ }^{*} p=0.0002$.

positively with venous epinephrine $(r=0.33$, $p<0.02)$ and heart rate $(r=0.38, p<0.01)$.

\section{DISCUSSION}

The present study shows that plasma norepinephrine correlates positively with blood pressure in 50year-old men with never-treated, established essential hypertension. A highly significant correlation was seen with plasma norepinephrine in both peripheral venous and arterial blood. However, only arterial concentrations were significantly elevated compared with those in a normotensive control group. Although plasma epinephrine, heart rate, and body weight were significantly increased in the hypertensive group, stepwise multiple regression analysis showed that arterial plasma norepinephrine was the only significant independent explanatory variable of the high blood pressure in the hypertensive group.

Plasma norepinephrine is derived by overspill from the sympathetic nerve endings. An increased level of plasma norepinephrine does not necessarily imply increased sympathetic tone, because changes in neuronal reuptake, or clearance, may also be responsible. ${ }^{11}$ Plasma norepinephrine represents only a small fraction of the amount released, and release of norepinephrine from many organs contributes to the level. ${ }^{12}$ Even in situations in which plasma norepinephrine adequately may reflect cardiovascular sympathetic tone, the overall effect on blood pressure, for example, may also depend on such factors as receptor sensitivity and affinity, amount of available receptors, and vascular reactivity.

With all these limitations on the assessment of sympathetic nerve activity by plasma norepinephrine concentration, the present findings of a $19 \%$ increase in arterial plasma norepinephrine in the hypertensive group and a large overlap between the two groups does not seem impressive. Therefore a factor more important than a moderate hypertensive-normotensive difference in plasma concentration may be a positive correlation between plasma norepinephrine and blood pressure. In our set of variables, plasma norepinephrine measured in arterial blood was the only independent predictor of blood pressure in the hypertensive group by stepwise multiple regression analysis $(r=0.51)$; i.e., $25 \%$ of variability 


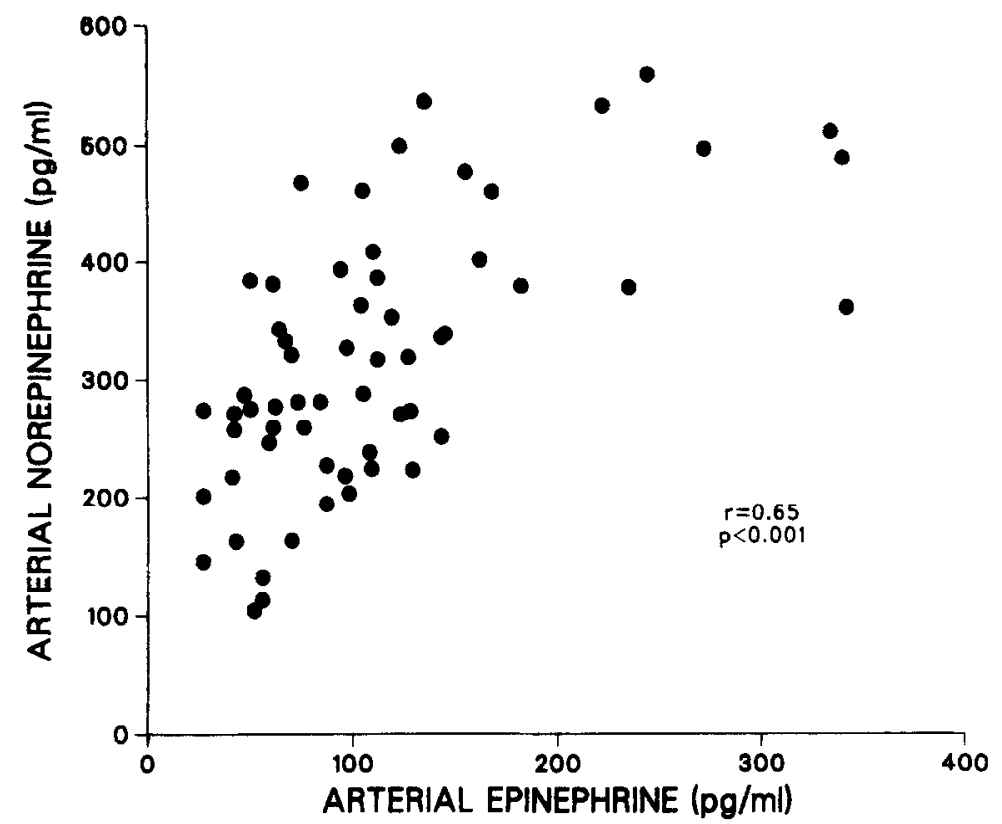

Fig. 3. Correlation between arterial plasma epinephrine concentration and arterial plasma norepinephrine concentration in the hypertensive group.

in blood pressure is explained by arterial norepinephrine. This correlation supports, but does not prove, a causal relationship between the activity of the sympathetic nervous system and high blood pressure.

As reviewed by Julius et al., ${ }^{13}$ a positive correlation between plasma norepinephrine and blood pressure has been found in several but not in all studies of plasma norepinephrine in essential hypertension, regardless of the actual plasma norepinephrine level. However, in all these studies reviewed, ${ }^{13}$ the correlation has been estimated on the basis of measurement of plasma norepinephrine in peripheral venous blood. An increased level of norepinephrine in hypertension may predominantly reflect increased sympathetic tone to the heart and kidneys. ${ }^{5}$ Muscle tissue contributes to approximately $50 \%$ of plasma norepinephrine in peripheral venous blood ${ }^{1}$ and sympathetic tone to muscle tissue ${ }^{3}$ seems to be unchanged in essential hypertension. These limitations of norepinephrine in antecubital venous blood compared with venous effluents from the heart or kidneys or of norepinephrine in atrial and arterial blood may partly or fully explain conflicting results concerning the correlation between plasma norepinephrine and blood pressure. ${ }^{13}$

The correlation between arterial plasma norepinephrine and blood pressure in the hypertensive group only was not caused by a wider range of blood pressure in the hypertensive group $(43 \mathrm{~mm} \mathrm{Hg}$ for mean blood pressure) compared with that in the normotensive group ( $39 \mathrm{~mm} \mathrm{Hg}$ ). Most likely the correlation was caused by raised sympathetic tone to such organs as the heart and kidneys, with higher blood pressure in the hypertensive group. ${ }^{5}$ In addition, the reactivity for a given plasma concentration may be higher with higher blood pressure, as found in studies of norepinephrine infusion in essential hypertension. ${ }^{14-17}$ Such increased vascular reactivity in essential hypertension may have been caused by increased $\alpha$-adrenergic sensitivity, ${ }^{18}$ arteriolar structural changes, ${ }^{19}$ or both.

The present data support our hypothesis ${ }^{7}$ that measurements of arterial compared to peripheral venous plasma norepinephrine may be a more sensitive tool for the detection of hypertensive-normotensive differences in 50-year-old white men. The same may be true for 40-year-old hypertensive subjects from the same population, ${ }^{20}$ and for young women with preeclampsia compared with normotensive pregnant women. ${ }^{21}$ Esler et al. ${ }^{5}$ and Egan et al. ${ }^{6}$ also found increased arterial plasma norepinephrine in agematched studies, but did not report peripheral venous plasma norepinephrine. A study by Goldstein ${ }^{22}$ showing both raised arterial and peripheral venous norepinephrine may, however, be invalid, since the patients were on average 10 years older than the control subjects and plasma norepinephrine increases with age. ${ }^{23}$ In addition, antihypertensive medication was discontinued only 2 weeks before the study ${ }^{22}$ and patients and controls were not recruited from the same population. ${ }^{22}$

Plasma epinephrine was $57 \%$ and $53 \%$ increased in arterial and venous blood in the hypertensive group, respectively. However, despite these considerable increments, elevated plasma epinephrine levels were found not to be an independent predictor of 
higher blood pressure within the hypertensive group. Since the first report of raised epinephrine in essential hypertension, ${ }^{24}$ the role of epinephrine in the pathogenesis of hypertension has been discussed, but far from clarified. One of the theories is that epinephrine may activate presynaptic $\beta_{2}$-adrenergic receptors that facilitate norepinephrine release from sympathetic nerves, causing hypertension. ${ }^{25,}{ }^{26}$ Along with this, a recent study ${ }^{27}$ showed that "stress" levels of epinephrine, achieved by infusion of epinephrine for 6 hours, caused a delayed and protracted pressor effect in human volunteers. Another opinion is that epinephrine is involved in the "arousal reaction" or early hyperkinetic state of hypertension, which will later result in compensatory vasoconstrictory responses and structural vascular changes. ${ }^{28} \mathrm{~A}$ considerable hypertensive-normotensive difference in plasma epinephrine could also be of significance for metabolic disturbances in hypertension, since physiologic epinephrine levels may be involved in the regulation of, for example, lipid and lipoprotein metabolism, ${ }^{29-31}$ glucose metabolism, ${ }^{32}$ and blood platelet function. ${ }^{30,33}$

In the hypertensive group, we found strong positive correlations between increased norepinephrine, epinephrine, and heart rate. Increased heart rate in essential hypertension may be caused by an increase of sympathetic tone, a decrease of parasympathetic tone, or by both. ${ }^{34}$ If another pathophysiologic mechanism other than altered autonomic function was operating, cardiac frequency would have been unchanged or even depressed by activated baroreflexes. Positive correlations may indicate covariation without causative relationship, i.e., both the noradrenergic and adrenergic divisions of the sympathetic nervous system may be activated in hypertension. On the other hand, a strong correlation between plasma epinephrine and norepinephrine in the hypertensive group $(r=0.65)$ may indicate that plasma epinephrine is involved in a process regulating the release of norepinephrine to plasma, such as stimulation of presynaptic $\beta$-adrenergic receptors. ${ }^{25,} 26$

Our hypertensive group had $9 \%$ higher body mass index than the normotensive group, but this does not seem to be the cause of the increased sympathetic tone in the hypertensive group. Thus plasma epinephrine showed a weak but significant negative correlation with body mass index $(r=-0.27)$ in the hypertensive group. In a recent report, ${ }^{35}$ a negative correlation between plasma catecholamines and percent body fat was explained as a mechanism promoting excessive storage of energy by decreasing sympathetic activity. If this holds true, even larger hypertensive-normotensive differences in plasma catecholamines could be expected in studies with groups precisely matched for body mass.
Mental stress may more easily create "arousal" with enhanced neurogenic activity of the type associated with the defense reaction in the hypertensive compared with the normotensive subjects. ${ }^{36}$ Merely the awareness of hypertension per s $\mathrm{s}^{37}$ may increase blood pressure and create "arousal" in young subjects in connection with a provocative maneuver such as a cold pressor test. Along with this, Ibsen et al. ${ }^{38}$ found no difference in plasma catecholamine levels between hypertensive and normotensive 40-year-old men when the hypertensive individuals were unaware of their high blood pressure. However, only peripheral venous and not arterial plasma catecholamines were measured by Ibsen et al. ${ }^{38}$ On the other hand, given this background of susceptibility of arousal in the hypertensive subjects (at least in those who are aware of their high blood pressure ${ }^{36,37}$ ), the act of arterial blood sampling per se, either by direct puncture as in the present and in a previous study, ${ }^{21}$ or by use of an indwelling catheter ${ }^{19,20.22}$ or even central venous catheters introduced into the heart and kidneys, ${ }^{\bar{\prime}}$ may induce an arousal reaction and raise the plasma catecholamines. Whether arterial plasma catecholamines are increased in hypertensive subjects unaware of their high blood pressure has yet to be determined.

In conclusion, in a group of white men, all 50 years of age, with never-treated, established essential hypertension, we found that arterial plasma norepinephrine significantly correlated positively with blood pressure. Arterial plasma norepinephrine was the only significant independent predictor of blood pressure in the hypertensive group, in spite of the fact that plasma epinephrine, heart rate, and body mass index showed larger hypertensive-normotensive differences than did plasma norepinephrine.

The authors are grateful for the constructive comments of Professor Stevo Julius. We would also like to thank Mrs. Ruth Amundsen, lechnician, Department of Internal Medicine, Ullevaal Hospital, Oslo, Norway, for expert laboratory work, and Ms. Barbara Stoner, Department of Internal Medicine, Division of $\mathrm{Hy}$ pertension, The University of Michigan Medical Center, Ann Arbor, Michigan, for typing the manuscript.

\section{REFERENCES}

1. Hjemdahl P. Plasma catecholamine determinations: analytical problems and interpretations. In: Christensen NJ, Henriksen O, Lassen NA, eds. The sympathoadrenal system: proceedings of the Alfred Benzon Symposium 23. Copenhagen: Munksgaard, 1986:17-37.

2. Wallin BG, Sundlof G, Eriksson B-M, Dominiak P, Grobecker H, Lindblad L-E. Plasma noradrenaline correlates to sympathetic muscle nerve activity in normotensive man. Acta Physiol Scand 1981;111:69-73.

3. Morlin C, Wallin BG, Eriksson BM. Muscle sympathetic activity and plasma noradrenaline in normotensive and hypertensive man. Acta Physiol Scand 1983;119:117-121.

4. Goldstein DS. Plasma catecholamines and essential hypertension. An analytical review. Hypertension 1983;5:86-99.

5. Esler M. Jennings G. Biviano B, Lambert G, Hasking G. 
Mechanism of elevated plasma noradrenaline in the course of essential hypertension. J Cardiovasc Pharmacol 1986;8(Suppl 5):S39-43.

6. Egan B, Panis R, Hinderliter A, Schork N, Julius S. Mechanism of increased alpha adrenergic vasoconstriction in human essential hypertension. J Clin Invest 1987;80:812-17.

7. Kjeldsen SE, Eide I, Aakesson I, Leren P. Increased arterial catecholamine concentrations in 50-year-old men with essential hypertension. Scand J Clin Lab Invest 1983;43:343-9.

8. Leren P, Askevold E-M, Foss OP, Froili A, Grymyr D, Helgeland A, Hjermann I, Holme I, Lund-Larsen PG, Norum KR. The Oslo Study: cardiovascular disease in middle-aged and young Oslo men. Acta Med Scand 1975; Suppl 588.

9. Peuler JD, Johnson GA. Simultaneous single radioenzymatic assay of plasma norepinephrine, epinephrine and dopamine. Life Sci 1977;21:625-36.

10. Kjeldsen SE, Flaaten B, Eide I, Helgeland A, Leren P. Fvidence of increased peripheral catecholamine release in patients with long-standing, untreated essential hypertension. Scand J Clin Lab Invest 1982;42:217-23.

11. Esler M, Jackman G, Bobik A, Leonard P, Kelleher D, Skews $H$, Jennings G, Korner P. Norepinephrine kinetics in essential hypertension. Defective neuronal uptake of norepinephrine in some patients. Hypertension 1981;3:149-56.

12. Brown MJ, Jenner DA, Allison DJ, Dollery CT. Variations in individual organ release of noradrenaline measured by an improved radioenzymatic technique: limitation of peripheral venous measurements in the assessment of sympathetic nervous activity. Clin Sci 1981;61:585-90.

13. Julius S, Ibsen H, Colfer HT. Hemodynamic and pharmacologic correlates of plasma norepinephrine in hypertension. In: Ziegler MG, Lake CR, eds. Norepinephrine. Vol. 2. Frontiers of clinical neuroscience. Baltimore: The Williams \& Wilkins Co, 1984:401-9.

14. Philipp T, Distler A, Cordes U. Sympathetic nervous system and blood pressure control in essential hypertension. Lancet 1978;2:959-63.

15. Meier A, Gubelin U, Weidmann P, Grimm M, Keusch G, Gluck 7, Minder I, Beretta-Piccoli C. Age-related profile of cardiovascular reactivity to norepinephrine and angiotensin II in normal and hypertensive man. Klin Wochenschr 1980; 58:1183-8.

16. Meier A, Weidmann P, Grimm M, Keusch G, Gluck Z, Minder I, Ziegler WH. Pressor factors and cardiovascular pressor re sponsiveness in borderline hypertension. Hypertension 1981;3:367-72.

17. Krakoff LR, Vlachakis ND, Mendlowitz M. Effect of posture, isometric hand-grip exercise and norepinephrine infusion in normal renin hypertensive patients. In: Laragh JH, Buhler FR, Seldin DW, eds. Frontiers in hypertension research. New York: Springer-Verlag, 1981:290-6.

18. Doyle AE, Fraser JRE, Marshall RJ. Reactivity of forearm vessels to vasoconstrictor substances in hypertensive and normotensive subjects. Clin Sci 1959;18:441-53.

19. Egan B, Schork N, Panis R, Hinderliter A. Vascular structure enhances regional resistance responses in mild essential hypertension. J Hypertens 1988;6:41-8.

20. Kjeldsen SE, Os I, Westheim A, Frederichsen P, Hjermann I Eide IK, Gautvik K. Decreased serum phosphate in essential hypertension: relation to increased sympathetic tone. Am $J$ Hypertens 1988;1:403-9.

21. Øian P, Kjeldsen SE, Eide I, Maltau JM. Increased arterial catecholamines in preeclampsia. Acta Obstet Gynecol Scand 1986;65:613-16.

22. Goldstein DS. Arterial baroreflex sensitivity, plasma catecholamines, and pressor responsiveness in essential hypertension. Circulation 1983;68:234-40.

23. Pedersen EB, Christensen NJ. Catecholamines in plasma and urine in patients with essential hypertension determined by double-isotope derivative techniques. Acta Med Scand 1975;198:373-7.

24. Franco-Morselli R, Elghozi JL, Joly E, DiGiuilio S, Meyer P. Increased plasma adrenaline concentrations in benign essential hypertension. Br Med J 1977;2:1251-4.

25. Rand MJ, Majewski $H$, Tung LH. Activation of prejunctional $\beta$-adrenoceptors by adrenaline acting as a co-transmitter: a possible cause of hypertension. Drugs 1983;25(Suppl 2):64-8.

26. Brown MJ, Macquin I. Is adrenaline the cause of essential hypertension? Lancet 1981;2:1079-82.

27. Blankestijn PJ, Man In't Veld AJ, Tulen J, van den Meiracker AH, Boomsma F, Moleman P, van Eck HJR, Derkx FHM, Mulder P, Lamberts SJ, Schalekamp MADH. Support for adrenaline-hypertension hypothesis: 18 hour pressor effect after 6 hours adrenaline infusion. Lancet 1988;2:1386-9.

28. Folkow B. Physiological aspects of primary hypertension. Physiol Rev 1982;62:347-503.

29. Staten MA, Matthews DE, Cryer PE, Bier DM. Physiological increments in epinephrine stimulate metabolic rate in humans. Am J Physiol 1987;253:E322-30.

30. Kjeldsen SE, Gjesdal K, Eide I, Aakesson I, Amundsen R, Foss $O P$, Leren $P$. Increased $\beta$-thromboglobulin in essential hypertension: interactions between arterial plasma adrenaline, platelet function and blood lipids. Acta Med Scand 1983; 213:369-73.

31. Dimsdale JE, Herd JA, Hartley LH. Epinephrine mediated increases in plasma cholesterol. Psychosom Med 1983;45:227. 32.

32. Clutter WE, Bier DM, Shah SD, Cryer PE. Epinephrine plasma metabolic clearance rates and physiologic thresholds for metabolic and hemodynamic actions in man. J Clin Invest 1980;66:94-101.

33. Lande K, Kjeldsen SE, Os I, Westheim A, Hjermann I, Eide I, Gjesdal K. Increased platelet and vascular smooth muscle reactivity to low-dose adrenaline infusion in mild essential hypertension. J Hypertens 1988;6:219-25.

34. Julius S, Pascual AV, London R. Role of parasympathetic inhibition in the hyperkinetic type of borderline hypertension. Circulation 1971;44:413-18.

35. Peterson HR, Rothschild M, Weinberg CR, Fell RD, McL eish KR, Pfeifer MA. Body fat and the activity of the autonomic nervous system. N Engl J Med 1988;318:1077-83.

36. Eliasson K, Hjemdahl P, Kahan T. Circulatory and sympathoadrenal responses to stress in borderline and established hypertension. J Hypertens 1983;1:131-9.

37. Rostrup M, Kjeldsen SE, Amúndsen R, Eide I. Does awareness of hypertension per se influence blood pressure, heart rate, plasma catecholamines and response to cold pressor test? $\mathrm{J}$ Hypertens 1988;6(Suppl 4):S743-4.

38. Ibsen H, Christensen NJ, Hollnagel H, Leth A, Kappelgaard AM, Giese J. Plasma noradrenaline concentration in hypertensive and normotensive forty-year-old individuals: relationship to plasma renin concentration. Scand J Clin Lab Invest 1980;40:333-9. 